\title{
The co-evolution of competition and parasitism in the resource-based view: a risk model of product counterfeiting
}

J. S. Busby, Department of Management Science, Lancaster University, Bailrigg, Lancaster LA1 4YX Email j.s.busby@lancaster.ac.uk

(Corresponding author)

\section{Abstract}

The primary concern in the resource-based view of the firm has been competition. For many firms, however, the relevant ecology includes parasites as well as competitors - notably product counterfeiters who parasitically exploit a firm's reputational resource. This parasitic process both diminishes the reputational resource it exploits, and produces significant risk of harm as a by-product. This article extends the resource-based view, presenting an account of the mechanism by which competition and parasitism co-evolve and produce a distinctive form of resource erosion. It does so using a model which, because a firm's reputational resource exists distributedly in the minds of mutually-influencing but not centrally-coordinated consumers, takes an agent-based approach. This model then naturally forms a basis for the probabilistic risk assessment of the consequences of parasitism - particularly the harm that arises from the counterfeiting of safety critical products such as pharmaceuticals. The intended contribution is to show how the resource-based view can be extended to reflect the fact that heterogeneous resource distribution is implicated in parasitism as much as competition, and to show how a model of the underlying mechanisms can support risk analysis.

Keywords: Multi-agent systems, resource-based view, reputational resources, parasitism, product counterfeiting, risk analysis

\section{Acknowledgements}

Many thanks are due to the anonymous reviewers of an earlier draft of this article for their insights and suggestions.

\section{Introduction}

The resource-based view (RBV) of the firm remains a long-standing theory of how firms survive under competition (Wernerfelt, 1984; Barney, 1991). Although it has met with a number of criticisms (Priem and Butler, 2001; Lado et al, 2006; Kraaijenbrink et al, 2010, Arend and Lévesque, 2010; Arend, 2015; Bromiley and Rau, 2016) - for example the indeterminate nature of its concepts, and its 
ambiguity about the source of resource value - it is still argued that 'no other perspective has effectively challenged its centrality to the field' (Pacheco-de-Almeida and Zemsky, 2007). And studies such as Makadok's (2001), Adner and Zemsky's (2006) and Bendoly's (2007), which provide analytical and computational models of the resource-based view, have given it a lot more precision.

Yet it is a theory that has not dealt with the fact that within many firms' ecologies there are not only competing conspecifics but also parasites - firms that engage in activities like counterfeiting, parasitically exploiting and undermining a legitimate firm's reputational resources. These reputational resources are central to a firm's viability for obvious reasons. Almost all goods and services are subject to strong information asymmetries (Akerlof, 1970) in which consumers typically know much less about the intrinsic quality of such goods and services than producers. This information asymmetry creates risks of producers providing poor quality, defective and even dangerous goods. Reputation thus becomes an important device for managing the risks to consumers - and therefore an important resource for producers competing for consumers' business. It is a particularly significant resource in experience good markets, where the inadvertent consumption of poor quality products is more likely and opportunism therefore more significant (Liebeskind and Rumelt, 1989). Nonetheless, the reputational resource is vulnerable to exploitation by imposters: to counterfeiters passing off substandard products as being those of a reputable producer. Institutions like trademark (Ramello, 2006) are attempts to mitigate the counterfeiting risk by establishing a legally-protected signal of identity. Yet safety-critical products such as pharmaceuticals can be counterfeited extensively and easily, with widespread consequences for public health (Liang, 2006; Jackson et al, 2012). This is particularly so in the developing world (Juillet and Vlasto, 2005; Cuomo and Mackey, 2014; Mackey et al, 2015), but by no means exclusively so, as indicated by the EU's adoption of a falsified medicines directive in 2011 (EU, 2011). This makes various provisions, for example, in relation to the pharmaceuticals supply chain. But it also specifically refers to devices that can facilitate verification of authenticity, and thus deals with the problem that general, reputational resources are insufficient to manage consumption risk and are themselves at risk. As well as reportedly being a growing problem in pharmaceutical supply chains (Pinho de Lima et al, 2018), for reasons ranging from globalization to the Internet, counterfeiting is similarly a widespread and growing concern in microelectronics supply chains (DiMase et al, 2016), with a US Senate inquiry (Senate, 2012) referring to 'a flood of counterfeit electronic parts' in the defence industry.

The premise of this article is that phenomena like counterfeiting are not incidental to competition but are bound up with a firm's attempts to be competitive, and therefore should be part of the resource-based theory of the firm. As in many ecologies, an entity that is successful in competition with its conspecifics becomes attractive to parasites that can draw on the benefits of a host's success. The resource-based view is incomplete as a theory of firm survival if it does not deal with parasitism - and may give incomplete if not contradictory indications of a firm's prospects. As argued below, for example, the inimitability criterion (Barney, 1991) for a competitive resource does not protect against 
parasites, and in fact attracts them, because they make no attempt to imitate the reputational resource, instead appropriating and exploiting it by impersonation.

A considerable problem in the study of parasitic processes like counterfeiting has been the lack of credible data (Wilson et al, 2016). Not only is the activity itself clandestine, but reporting counterfeits can undermine the reputational resource of genuine producers. This absence of empirical knowledge makes it especially important to develop our understanding by modelling: by expressing what we believe to be the mechanisms underlying counterfeiting, and by exploring the outcomes created by them. In the absence of empirical data it also becomes the main coherent support for decision makers, both those in public agencies concerned with regulation and public health, and those within firms specifically concerned about dangerous counterfeits of their products. Epstein (2008) offers a wide variety of reasons for modelling of this kind, well beyond these considerations - but these include the training of practitioners and disciplining the policy dialogue. He also makes the key point that 'Without models... it is not always clear what data to collect'. Smith and Rand (2018) similarly advocate agent-based modelling in order inter alia to develop theory for subsequent empirical exploration.

Agent-based modelling is particularly indicated in this case because the reputational resource, although notionally belonging to a firm, exists primarily as beliefs in the minds of a distributed and heterogeneous population of consumers. Representing their interactions and consumption decisions is most directly achieved with an agent-based model. This also offers what has been characterized as a 'demand-side' perspective (Adner and Zemsky, 2006; Chauradia et al, 2018) on the resource-based view: resource value is created for the consumer (before being captured by the firm) because reputation manages consumer risk and informs consumer choice.

The aim of this article is therefore to explore, through agent-based modelling, 1) how we should extend the resource-based view in order to be a satisfactory theory of a firm existing in an ecology of both competitors and counterfeiters, and 2) how a model of the mechanisms through which competition and counterfeiting evolve can form a basis for assessing the risks arising from counterfeiting in the case of products such as pharmaceuticals. In the remainder of the article there is an account of how the resource-based view can be extended in this way, followed by the development of an agent-based model, and an account of how simulation yields insights about the kind of risks that are incurred through counterfeiting. Finally, there is a discussion of the implications of the work and its limitations.

\section{The relevant literature and the need for a theory of parasitism}

\subsection{The resource-based view and the missing account of parasitism}

The central focus of the resource based view of the firm is on competition, and the heterogeneous 
endowment of bundles of persistent resources that confer competitive advantage due to their valuable, rare, imperfectly imitable and non-substitutable characteristics (Barney, 1991; Wernerfelt, 2016). It is an attractively general theory that has been taken up in a variety of disciplines (for recent examples see Hitt et al, 2016; Kull et al, 2016), although not always approvingly (Bromiley and Rau, 2016). The resource at issue in counterfeiting is a producer's reputation for quality: for reliable, durable, safe goods that are free from contaminants, by-products and defects. Reputation is regarded as 'a key resource' (Scott and Walsham, 2005), the outcome of a long-term process of development and so among the hardest of all resources to imitate (Roberts and Dowling, 2002). It is thus a classically heterogeneous resource that is central to a firm's competitiveness. It also has path dependence, arising from a succession of products, claims and consumption experiences. It has causal ambiguity, producing competitive advantage through subjective, contingent routes. And it is socially complex, requiring a coherent effort over multiple specialized actors to build and maintain (Barney, 1999; Bowman and Ambrosini, 2003; Branco and Rodrigues, 2006). Reputational resources are what shape external actors' responses to the firm given the inevitable discrepancy between 'what is known inside the firm and what is known externally' (Teece at al, 1997).

Inimitability is sometimes regarded as the most important aspect of resource-based theory. There are many ways of obtaining inimitability (Newbert, 2007), and the reputational resource is inherently inimitable because it specifically concerns the identity of its holder, creating a clear resource barrier against competitors (Wernerfelt, 1984) who are new, untried or in some way discredited. Yet the counterfeiter circumvents this inimitability. It does not imitate the reputational resource, but imitates the host's products and imitates devices proving their authenticity (like trademark, and third party certification) in order to impersonate the host. It thus avoids the need for what Teece et al (1997) refer to as 'replication' - the transfer of resources from one economic setting to another. There is a natural isolating mechanism (Rumelt, 1984) inherent in reputation as a resource: it has a uniqueness that comes from a lengthy process of demonstrating capability. But this isolating mechanism is bypassed in the counterfeiter's strategy of being an imposter and thus appropriating but not imitating reputation. This means that the inimitability of the target firm's reputational resource, far from being a barrier, in fact becomes an attraction to the counterfeiter.

This process is closely analogous to that of biological parasitism. As in most cases of biological parasitism, counterfeiting depletes the host resource it exploits and can thus become selflimiting. If counterfeits penetrate the market to too great a degree this will destroy the value of the host's reputational resource and the parasite will itself fail unless it finds another host. As with other parasitic processes, it also creates harmful by-products such as physical danger and loss. And the relationship between host and parasite differs radically from that between host and competitors. Advertising and promotion by the legitimate producer are not usually beneficial to its competitors yet are usually beneficial to the parasite (Mackenzie, 2010), for example. A host signaling its strengths to deter competitors or entice consumers attracts parasites, as will the measures a host takes to protect its 
reputation. It is even possible that, if counterfeiters operate exclusively in markets not already exploited by the legitimate producer, the parasitic relationship can become symbiotic (Lahiri and Day, 2013).

Perhaps the closest the RBV literature has come to parasitism is work on how one firm can gain access to another's resources through inter-firm linkages (Lavie, 2006; Hitt et al, 2016) and how, at the same time, this can also facilitate access by competitors (Mesquita et al, 2008; Hitt et al, 2016; Chauradia et al, 2018). This is connected to recent work challenging the view that resources have to be controlled in order to secure competitive advantage (Alexy et al, 2018). Both issues are especially interesting in the case of reputational resources - where the possibilities of legitimately appropriating value from an associated organization's reputation, and the difficulties of maintaining control, can be central issues for a firm. They are also issues that are likely to be regarded with ambivalence, holding out the possibilities of both enhancing and undermining competitive advantage. Thus a more nuanced understanding of the RBV has emerged - in which control may not be central to competitive advantage, and relationships among firms may confer access to others' resources. But there is still a need for a substantial step further: to deal with the general problem of parasitism on valuable resources and the emergence of parasites as a group distinct from a firm's competing conspecifics.

The issue of resource control is also strongly influenced by the fact that, although reputation belongs as a resource to a producer, it really exists as a state of consumers' minds. It is the kind of resource that the resource-based literature sometimes refers to as being subjective (Kor et al, 2007). It is in various senses owned by the producer, but it exists in the minds of others, and those others are reasoning, adaptive agents - not passive repositories. Moreover, these consumers are heterogeneous, holding non-identical views of the producer, yet at the same time influencing each other. We know from empirical studies such as those of Scherer and Cho (2003) and subsequently Muter et al (2013) that there are strong social contagion effects in which dyadic ties between individual risk perceivers have a strong influence on their perceptions of risks such as those of poor product quality. Ultimately, then, the extension of the resource-based view from competition to competition plus parasitism does not just involve taking account of behaviour in a group of parasites - but must also deal with the interrelated behaviour in a population of consumers. This also becomes an important consideration for the choice of modelling medium.

\subsection{The case for agent-based modelling in representing parasitism}

Existing models of product counterfeiting are based on a traditional normative approach of utility maximization among consumers without reference to the resource-based view. They generally refer back to two seminal articles by Grossman and Shapiro (1988a, 1988b). Several studies, including Grossman and Shapiro's (1988b) second, are specifically concerned with what they refer to as 'nondeceptive' counterfeiting. Given the WTO (2011) definition of counterfeiting as 'deceiving the purchaser into believing that he/she is buying the original goods', these really produce models of 
competition not counterfeiting. Qian et al's (2015) model allows 'non-deceptive counterfeiting', as does Zhang et al's (2012) and Cho et al's (2015). Models such as Cho et al's (2015) also equate the perceived quality of a product with its 'real quality', thereby assuming away the obvious information asymmetry that lies behind the value of reputation as a resource. The whole problem is that consumers cannot 'perceive' the objective quality of what they might choose to consume. There is also a closely related literature that specifically models the 'piracy' of information goods, and Lahiri and Dey's (2013) study provides a recent example and summary of this literature. But again this typically lacks the defining element of deception. Moreover the emphasis of existing models is on equilibria of one kind or another, both economic (Grossman and Shapiro, 1988a) and game theoretic (Qian et al, 2015; Cho et al, 2015) - not on the dynamics of a process or on the normal choice processes of actors faced with bounded rationality. It is the dynamics of counterfeiting processes that producers and other actors actually experience, and that produce the risk of consuming harmful goods.

To extend resource-based theory what is needed is a model of firms interacting over time through processes of competition and parasitism, responding to the dynamics of those processes as they experience them, and having decision rules whose simplicity and transparency reflect bounded rationality and the need for ecological validity (Gigerenzer and Brighton, 2009). At the end of Section 2.1 an argument was also made that reputational resources, although belonging to a producer, exist more directly in the minds of a population of distributed, heterogeneous consumers who interact among themselves as well as with producers and counterfeiters. All this suggests a need for agentbased modelling, which is especially indicated when multiple actors interact without central coordination (Macy and Willer, 2002), following rules whose collective effects are hard to deduce (Axelrod,1997: 4), and having a diversity of qualities that shape the behaviour of the system (Macal and North, 2010). It is suited to problems such as understanding resource allocation processes that are hard to study empirically (Coen and Maritan, 2011). And it has been particularly linked by sociologists to the process-theoretic tradition in social theory (Cederman, 2005). As Miller (2015) argues, 'Specifying agent-based models promotes ontological clarity by focusing researchers' attention on the properties and relations of people and things, and their dynamics'. This concern with dynamics is not the exclusive preserve of agent-based modelling, and systems dynamics is an alternative medium that has been used to model the RBV in particular (Rahmandad, 2012). Like agent-based approaches, systems dynamics produces computational, 'complex system' models (Carley, 2009; Rahmandad and Sterman, 2008). But the distinguishing feature of agent-based models is that they offer a direct representation of agents, like firms, consumers and counterfeiters, and the social networks in which they interact. This is an important quality of Bendoly's (2007) computational model of mutual resource enablement in the resource-based view, for example, and of Amini et al's (2012) model of product diffusion. Agents like consumers can be depicted as being as heterogeneous as suits the context (Stummer et al, 2015). In contrast, Adner and Zemsky's (2006) analytical model of the resource-based view represents consumer heterogeneity with only two classes 
of consumer and does not deal with the interactions among them. Moreover, the direct representation of agents means that agent-based models offer the clearest way of portraying the agents' bounded rationality (Stummer et al, 2015), and the naturally heuristic nature of human responses to uncertainty (Tversky and Kahneman, 1974; Gigerenzer and Goldstein, 1996).

Since reputation essentially concerns the way in which consumers manage their consumption risk, the most relevant recent developments in the $\mathrm{ABM}$ literature are those dealing with the way in which collective risk responses develop as individuals exchange risk signals. Recent work using agent based models to develop insight into collective risk responses includes studies on social risk amplification (Busby et al, 2016), the dissemination of risk warnings (Nagarajan et al, 2012), and how collective risk responses shape the underlying risk they are responding to (Tonn and Guikema, 2018). The key issue in this kind of work is the recursive connection between risk perceptions and objective risk, mediated by the social interaction of the risk perceivers. Different studies in this area have modelled this interaction in different ways: Busby et al's model (2016), for example, was based on individuals responding through availability heuristics. But they share the basic setup in which some kind of focal, organizational agent - or group of agents - is trying to manage the way a distributed group of other agents responds to signals it receives about failure or disruption in the focal organization's capacities. As with the problem of parasitism and counterfeiting, the underlying phenomenon, whether it is some physical disaster, a disease outbreak or some economic threat, only becomes a threat to an organization when it is a threat to some other population and becomes the object of that population's attention. The organization's central concern is then the dynamics of this population's response over time.

An agent-based model is therefore developed in the next section in order to explore how the resource-based view should be extended to deal with parasitism, and counterfeiting in particular. An 'agent' in this model is always a social entity: a human or organization, equipped with behavioural capacities that define the mechanism (Miller, 2015) which produces and modifies reputations. It is this direct representation of social entities that makes agent modelling especially well-suited to theories like the RBV whose concern is with the advantage of a particular firm in relation to other firms within some common group. A 'resource', in contrast, is conventionally a stock or supply of some kind whose use provides benefit to some agent. This creates a risk of tautology in the RBV (Priem and Butler, 2001; Arend, 2015)), because a resource defined by being beneficial is theorised to be the cause of a beneficial outcome. But, in the model that follows, a reputational resource is only a resource in the sense that it participates in various agents' decision rules.

\section{Developing a model of reputation, competition and parasitism}

\subsection{The starting point: producers, consumers and reputation}


The aim of the model that follows is to explore how to represent a resource-based theory extended to deal with parasitism co-evolving with competition. At various points this uses the context of pharmaceuticals as a motivating example, but avoids where possible idiosyncratic aspects of pharmaceuticals that are irrelevant to other cases. As acknowledged later, models that inform practice are ways of addressing idiosyncrasy as much as they are ways of addressing general processes of competition and parasitism - but the concern here is with these general processes.

The basis of the model is a small set of legitimate producers, $p \in P$, who produce a product that is functionally the same but can have systematic quality differences. A producer $p$ 's reputational resource is central to the model, but this exists in the scalar evaluations of individuals within a population of consumers $c \in C$, as $r_{c p} \in[0,1]$. These evaluations $r_{c p}$ are initially endowed with values sampled from a beta distribution, $r_{c p}(t=0)=\operatorname{Beta}[\alpha, \beta]$ whose parameters are model constants. The aggregate reputation for $p$ is the sum of these:

$$
r_{p}=\sum_{c \in C} r_{c p}
$$

This naturally makes the reputational resource socially complex and path dependent, following the specific processes - outlined below - by which the $r_{c p}(t)$ distributed over the consumer population evolve. This is a substantially different approach from that of more analytical models such as Cabral's (2016) in which reputation is represented as a function, directly, of prior reputation and quality.

Whenever a consumer $c$ is active, it updates its reputational evaluation of $p$ in the light of its neighbours' evaluations. As Amini et al (2012) argue, neglecting this local interaction or 'word of mouth' process in the consuming population leads to poor policy conclusions. Consumers are embedded in some social network represented by an unweighted graph $G$ where $c$ and $d$ are neighbours if $G_{c d}=1$, and not if $G_{c d}=0$. The immediate neighbourhood of $c$ is $N(c)=\left\{d \in C \mid G_{c d}=\right.$ $1\}$. The simplest rule for updating its reputational evaluation of producer $p$ is that $c$ takes a weighted mean of its own and its neighbours' evaluations in the prior period. All neighbours' evaluations are given equal weight and, despite the obvious limitations of this procedure, the validity of equal weighting or 'tallying' has been shown to be surprisingly strong (Gigerenzer and Brighton, 2009). It is straightforward to incorporate refinements - for example Amini et al (2012) argue that negative wordof-mouth has a greater effect than positive, and Stummer et al (2015) similarly suggest that consumers are more likely to communicate information that reduces utility valuations. The relative importance of its neighbours' views is based on the consumer's credulity (that is, open-ness to influence by others' opinions), $y_{c}$, such that

$$
r_{c p}(t)=\left(1-y_{c}\right) r_{c p}(t-1)+y_{c} \sum_{d \in N(c)} r_{d p}(t-1) /|N(c)|
$$

All models of this kind need some representation of credulity although it often goes by different labels: Amini et al (2012) for example refer to a 'coefficient of imitation'. The values of $y_{c} \in[0,1]$ are randomly endowed from a uniform distribution and do not change. There is thus a diffusion 
process in the social network, but it is a diffusion process that co-exists with an experiential process, as explained below. The model excludes the possibility that reputational evaluations would also be influenced by broadcast news events, but could readily be extended to incorporate such events. It is also worth saying that, although a model in which interaction solely consists of this exchange of reputational evaluations appears very limited, it has some justification. Moussaid et al's (2015) study suggested that specific messages become distorted as they are diffused through chains of inter-individual interaction, but that the perception of risk is transmitted more faithfully because individuals shape their messages accordingly.

When it is active at any time $t$, a producer $p$ sets a price $q_{p} \in[0,1]$ that is a weighted mean of prior price and reputation, $q_{p}(t)=w_{p, t} q_{p}(t-1)+\left(1-w_{p, t}\right) r_{p}(t-1)$, where $w_{p, t}$ is randomly sampled from a uniform distribution at $t$ and prices are randomly endowed at $t=0$. Thus prices have inertia but follow reputation. In practice there are many other possibilities for producers' price updating rules, and evidence on just how prices behave depends very much on context. See for example Weiss (2006). A consumer $c$, when active at $t$, makes a choice of one producer $k_{c} \in P$. This choice is based on its own reputational evaluation $r_{c p}$ of $p$, and the product price $q_{p}$. It is important to make the choice stochastic as there are clearly other factors that shape consumer decisions. So the model represents $c$ as choosing $p$ randomly with a probability proportional to the reputation-to-price quotient. Thus the choice $k_{c}$ is sampled from a distribution over the producers where

$$
\operatorname{Prob}\left[k_{c}=p\right]=\left(r_{c p} / q_{p}\right) / \sum_{\pi \in P}\left(r_{c \pi} / q_{\pi}\right)
$$

Use of a stochastic decision rule allows for mistakes, as well as the unspecified effect of other influences on the choice. Wood et al (2016) similarly use probabilistic rules of behaviour in their analysis, but Stummer et al (2015) specify deterministic rules with a random error term to allow for mistakes. The central role played by reputation in this simple decision rule reflects its risk-managing function for the consumer, outlined earlier. Once consumers have chosen a producer they do not necessarily consume, as it might be that counterfeiting has become so rife that even the most attractive producer still presents an unacceptable risk. So consumer $c$ makes a stochastic decision to consume or not, $l_{c} \in\{0,1\}$. It is unlikely a pharmaceutical consumer would stop consuming unless its reputational evaluation had become very poor, so the consumption probability is set to a highly concave function of $r_{c p}$. But this assumption is tentative and really needs empirical investigation in any given context:

$$
\operatorname{Prob}\left[l_{c}=1 \mid k_{c}=p\right]=r_{c p}^{0.2}
$$

Either a consumer consumes one unit of product or nothing at whatever time it is active. This produces a consumer base for $p$ as $Z(p)=\left\{c \in C \mid k_{c}=p \cap l_{c}=1\right\}$ and a demand for its products as $z_{p}=$ $|Z(p)|$. The assumption, like Adner and Zemsky's (2006), is that within the limits of the situations produced by the model there are no capacity constraints on the firm. A producer's competitiveness is defined by the demand $z_{p}$, but this demand might be partly met by counterfeits. The producer's 
revenues are thus not determined by reputation through a direct functional connection, as they are in Cabral's (2016) model, but emerge from a process of reputation-shaped consumption choices.

\subsection{Counterfeiters and the consumption of counterfeits}

There is a small set of counterfeiters, $f \in F$, who individually choose which producer $p$ to target according to an attractiveness based on producers' reputations, $r_{p}$, and prices $q_{p}$. It is thus assumed that counterfeiters can estimate a producer's net reputation. For counterfeiters, as for consumers, high reputation is attractive - as suggested above. But, unlike for consumers, so is high price. Therefore the counterfeiter $f$ makes a choice of one producer to target, $u_{f} \in P$, such that the probability of choosing $p$ is proportional to the product of the producer's total reputation and price:

$$
\operatorname{Prob}\left[u_{f}=p\right]=r_{p} q_{p} / \sum_{\pi \in P} r_{\pi} q_{\pi}
$$

It is assumed the counterfeiters face equal costs, irrespective of their target. For the purposes of developing a model specifically of the role of reputational resources, counterfeiters' cost structures are ignored. But in reality these can be complex, and complexly related to potential payoffs. Specific aspects of supply chain structure and differences in jurisdiction along supply chains also plainly make a difference to costs (especially penalties and risks).

Having chosen the target, the counterfeiter also chooses a level at which to counterfeit, as some fraction $e_{f} \in[0,1]$ of the legitimate producer's production level. The choice of $e_{f}$ is strongly related to price, since the higher the price the greater the potential revenue for the counterfeiter and the more tolerable the risks. In this simple model the two are simply equated, since prices lie in $[0,1]$. Thus if $u_{f}=p$ then $e_{f}=q_{p}$. It is assumed that counterfeiters charge the same price as the genuine product, in order to avoid signalling that their products might be counterfeits.

The proportion of products available that appear to be those of $p$, but are actually counterfeits, at any one time will be

$$
b_{p}=\sum_{f \in F \mid u(f)=p} e_{f} /\left(1+\sum_{f \in F \mid u(f)=p} e_{f}\right)
$$

This is also the probability that a consumer $c$ who has chosen to consume producer $p$ 's product will inadvertently consume a counterfeit. So the actual experience $x_{c} \in\{0,1\}$ of $c$ consuming a counterfeit at any time $t$ at which $c$ is active occurs at random according to

$$
\operatorname{Prob}\left[x_{c}(t)=1 \mid k_{c}=p\right]=b_{p}
$$

An important assumption is that the product is neither a 'search' good (Nelson, 1970) whose quality is completely evident before it is chosen, nor a 'credence' good (Dulleck and Kerschbamer, 2006) whose quality is not known even when consumed. Instead it is an 'experience' good whose quality becomes evident when consumed. In Qian et al's (2015) study a given product has both searchable and experiential qualities (for example appearance and functionality). To keep the model parsimonious, however, here a consumer $c$ consuming producer $p$ 's product detects if it is counterfeit immediately 
after consumption. The assumption is also made that the consumer does not choose to knowingly consume a counterfeit. There are obviously markets in which counterfeits are consumed intentionally for a variety of reasons (Cordell et al, 1996; Veloutsou and Bian, 2008; Chaudhry and Stumpf, 2011). These tend not to be markets for safety critical products, but this is not necessarily the case.

On detecting a counterfeit, consumers revise their reputational evaluations. Loewenstein and Mather (1990) find evidence for a 'surprise' effect, suggesting that when consumers encounter counterfeits, the adjustments to their reputational evaluations should be proportional to those evaluations. It is assumed that the proportionality constant is identical for all consumers, $M_{\text {counterfeit }}<$ 1. If the consumer encounters a genuine item, there is a corresponding and much smaller adjustment in the opposite sense, $M_{\text {genuine }}<<1$. So, for a consumer $c$ active at time $t$, if $k_{c}=p$ (the consumer has chosen $p$ ) and $x_{c}(t)=1$ (the consumer has encountered a counterfeit) then

$$
r_{c p}(t+1)=r_{c p}(t)-M_{\text {counterfeit }} r_{c p}(t)
$$

Otherwise, if $x_{c}(t)=0$,

$$
r_{c p}(t+1)=\operatorname{Min}\left[r_{c p}(t)+M_{\text {genuine }} r_{c p}(t), 1\right]
$$

Asymmetry in the development of trust (for example Poortinga and Pidgeon, 2004) and the reputational effect of surprises, central to Cabral's (2016) study, indicates that $M_{\text {counterfeit }}>>M_{\text {genuine }}$. The consumer $c$ experiencing consumption of a counterfeit also communicates with its immediate neighbours $d$ in the social network, $N(c)$, causing them also to re-evaluate $p$ 's reputation by taking a weighted mean of their prior evaluations and $c$ 's re-evaluation. The weight is again the consumers' credulity, $y_{d}$ :

$$
\forall d \in N(c): r_{d p}(t+1)=\left(1-y_{d}\right) r_{d p}(t)+y_{d} r_{c p}(t+1)
$$

Figure 1 shows the main interactions among the agents defining the system at this stage, through these decision rules. The ' $\leftarrow$ ' symbol, as in ' $y \leftarrow x$ ', indicates that $x$ directly influences $y$ through a decision rule in the model. 


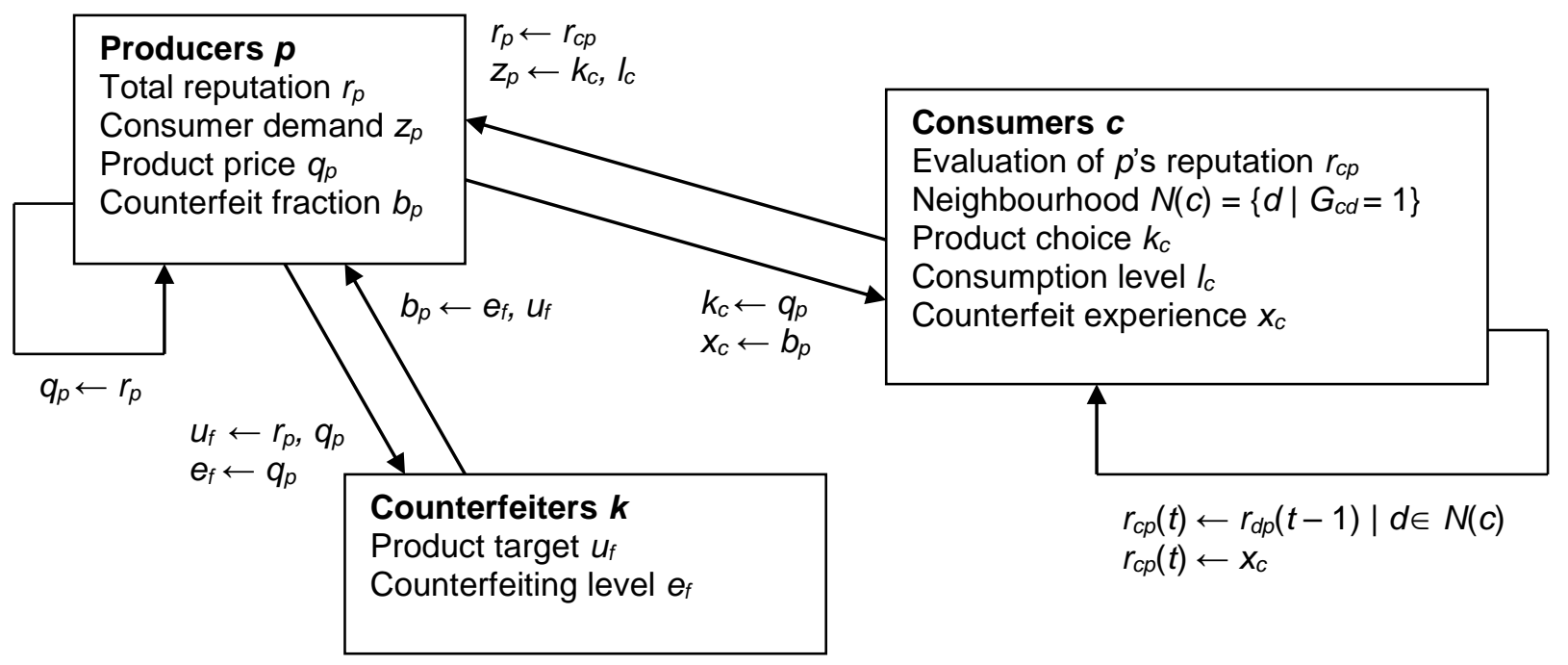

Figure 1. The initial interactions defining the agent-based model

This analysis differs substantially from the more standard analysis of markets for experience goods under uncertainty. In Liebeskind and Rumelt's (1989) analysis, the issue is whether a consumer's experience of a poor-quality product can be blamed on the producer, or chance, because if the former then the consumer would boycott the producer. In the counterfeiting case there is an a priori uncertainty for the consumer about whether they have bought a counterfeit but, if they find out they have, then they may well switch if there is an alternative producer. There is no uncertainty about attribution at that point.

\subsection{Adding retaliation and deterrence}

Detection and prosecution or other counter-action are most dependent on the level of counterfeiting activity. Very low levels are unlikely to provoke either the legitimate producer or the authorities to take action. But this retaliation is stochastic as it depends on other factors, such as good intelligence about counterfeits through distributor networks, and its timing is uncertain. In the model each counterfeiter $f$ is in a state of being retaliated against, $v_{f} \in\{0,1\}$, and when the counterfeiter is active the probability that retaliation is initiated is proportional to the counterfeiter's production level, $e_{f}$, according to a constant $V$ common to all producers:

$$
\operatorname{Prob}\left[v_{f}(t)=1\right]=V e_{f}(t)
$$

When retaliation is initiated, $f$ 's fractional production level $e_{f}$ is forced to zero for some period $U$. At all other times $e_{f}$ is set by the decision rule indicated above. $U$ is a model constant and identical for all counterfeiters. The literature indicates that even technological responses, such as holographic marking, are only temporarily effective (Newton et al, 2006), but in specific contexts this effect can be made more complex - for example, reducing counterfeit availability by some declining fraction. 
Another possibility is for a legitimate producer to deter rather than retaliate against counterfeits. This might involve enhancing the product's intrinsic quality or protecting the distribution infrastructure - for example using tracking technology such as RFID (Cannon et al., 2008). Evidence about the effectiveness of such investments appears mixed, especially when they apply to the packaging rather than the product itself (Liang, 2006). Therefore, the model is extended such that a producer $p$, with some probability that is proportional to the extent to which its product is being counterfeited, either invests or not in anti-counterfeiting measures, as recorded by $i_{p} \in\{0,1\}$ :

$$
\operatorname{Prob}\left[i_{p}=1\right]=W b_{p}
$$

The constant $W$ is identical for all producers. The effect of the investment is to increase the producer's price $q_{p}$ by some multiple, a model constant $Q>1$, to $Q q_{p}$, but also to create some deterrent to the counterfeiter, another model constant $D>1$. These are related, in the sense that we would expect the more costly deterrents, with higher $Q$, to producer greater deterrence $D$, but the relationship is not determinate as producers will have a range of deterrents of varying cost effectiveness to choose from. How closely price reflects the producer's extra cost is as usual highly context dependent, but in almost any realistic case deterrence will be costly to the producer, either directly or indirectly. The deterrent, in itself and independently of reputation, reduces the attractiveness of $p$ as a target for the counterfeiters from $r_{p} q_{p}$ (as specified above) to $r_{p} q_{p} / D$, but the increase in price to $Q q_{p}$ raises this, to $r_{p} q_{p} Q / D$. So, modifying the earlier rule, the counterfeiter's probability of choosing to counterfeit $p$ is now:

$$
\operatorname{Prob}\left[u_{f}=p\right]=\left(r_{p} q_{p} Q / D\right) /\left(\left(r_{p} q_{p} Q / D\right)+\sum_{\pi \in P, i(\pi)=0} r_{\pi} q_{\pi}+\sum_{\pi \in P, i(\pi)=1} r_{\pi} q_{\pi} Q / D\right) .
$$

The treatment of retaliation and deterrence can be made much more complex than this, and both may also involve dealing with infringements of patents or copyright as well as trademark. The model as presented here deals specifically with counterfeiting - with the way a counterfeiter appropriates a legitimate firm's reputation. It does not deal with infringement of patent or copyright, and the way in which a firm's expertise is appropriated (Stevenson and Busby, 2015). The two can go togetherwhere the counterfeiter copies a product's patented function, for example. But it might not, and it is certainly conceivable that a pharmaceutical counterfeiter would copy the product's appearance but not incorporate the active ingredient. The other problem with both deterrence and retaliation decisions is that they are essentially tactical responses that might be at odds with the legitimate producer's longerterm, strategic goals (for a recent study of this interaction see Hardcopf et al, 2017). Extending the model in this direction is beyond the scope of this article. But it is a reminder that actions taken in the short term to deal with parasitism can undermine longer term strategies to deal with competition.

\subsection{Adding recreancy and disclosure}

A further consideration is the conduct of the producers, in particular if and when they disclose the fact that their products are being counterfeited. On the one hand, disclosure may undermine reputation as 
it conveys information that there is a non-zero probability a consumer will consume a counterfeit. On the other hand, a failure to disclose the presence of counterfeits, when a consumer makes the discovery through other channels, will also undermine reputation through loss of trust. The failure to disclose is perhaps the simplest and most obvious manifestation of recreancy (Freudenberg, 1993). The issues associated with disclosure in relation to pharmaceutical counterfeiting, specifically, are discussed in detail by Cockburn et al (2005). In the model, producer $p$ discloses or not the fact that its products are being counterfeited, as recorded by $y_{p} \in\{0,1\}$, with a probability equal to the extent of this counterfeiting, $b_{p}$ (from above):

$$
\operatorname{Prob}\left[y_{p}=1\right]=b_{p}
$$

The disclosure remains in existence unless and until $p$ reverses this decision using the same rule. This decision rule is the same as that which triggers investment in anti-counterfeiting measures, described earlier, but both are stochastic so the decisions are not always in the same direction. Then, if a consumer $c$ consumes a counterfeit and a disclosure from the relevant producer $p$ is in force, i.e. if $k_{c}=$ $p, x_{c}(t)=1$ and $y_{p}=1$, the potential reputational damage described above is ameliorated by a model constant $Y<1$ such that:

$$
r_{c p}(t+1)=\operatorname{Min}\left[(1+Y)\left(r_{c p}(t)-M_{\text {counterfeit }} r_{c p}(t)\right), 1\right]
$$

Otherwise, if $y_{p}=0$ (there is no disclosure from the producer) then as before:

$$
r_{c p}(t+1)=r_{c p}(t)-M_{\text {counterfeit }} r_{c p}(t)
$$

The effect is propagated, as with all the other effects on reputation, through the social network. So the disclosure decision affects consumption decisions, and thereby consumption risk, as discussed below.

\section{Using the model to assess risk}

\subsection{A simulation of the model}

In this section the aim is to show, through simulation, how an agent-based model of this kind can produce insights into the outcomes generated by the mechanisms just specified - estimating uncertain, harmful outcomes in particular. The model was simulated in this instance for a simple system of three producers, two counterfeiters and 1000 consumers, subsequently compared with somewhat larger group sizes. The consumers' social network was based on Barabasi and Albert's (1999) observation that most real networks exhibit preferential connectivity. Thus the network is generated by randomly linking pairs of nodes with a probability equal to the relative connectedness of those nodes, until the average link degree reaches some level $L$, a model parameter. Amini et al (2012), in contrast, use a random network structure without preferential attachment, whereas Stummer et al (2015) use a more complex algorithm producing small-world and scale-free properties that also incorporates geographical disposition. But, as indicated below, in this case the outcomes are relatively insensitive to network structure. The simulation period is divided into 5000 discrete 'ticks'. At periods of 5, 30 
and 1 ticks, respectively, one of each type of agent (producer, counterfeiter and consumer) is selected at random, with equal probability, for activation and the decision rules applied. Consumption, and the experience of consuming a counterfeit, can only take place at the site of an activated consumer. There is no specific relation between simulation ticks and metric time, but these activation periods reflect the relative timescales in which the agents are assumed to operate. Counterfeiters, although they typically face vastly less work than legitimate producers in introducing a new product, nonetheless require a finite time to switch - for example in producing authentic packaging. The consumer switching decision is effectively instantaneous, and the producer decisions within the model scope (revised pricing) are also likely to be relatively quick. But these are assumptions about situations, and can obviously be adapted for situations that are believed to differ. The simulation is initialised with consumers' credulities sampled from a beta distribution symmetrical over $[0,1]$, consumers' reputational evaluations sampled from an asymmetric distribution (thus starting the simulation with producer reputations random but mostly intact), counterfeiters' initial production levels set at zero, and producers' initial prices also sampled from a symmetrical distribution. Model parameters were assigned minimum, modal and maximum values (indicated in the next sub-section) and sampled from beta distributions for each run of the simulation, written in Java under JDK1.7.0_7. Figure 2 illustrates the simulation schematically: agents are activated asynchronously and different agent types influence each other via the combined outcomes of their decision rules. 


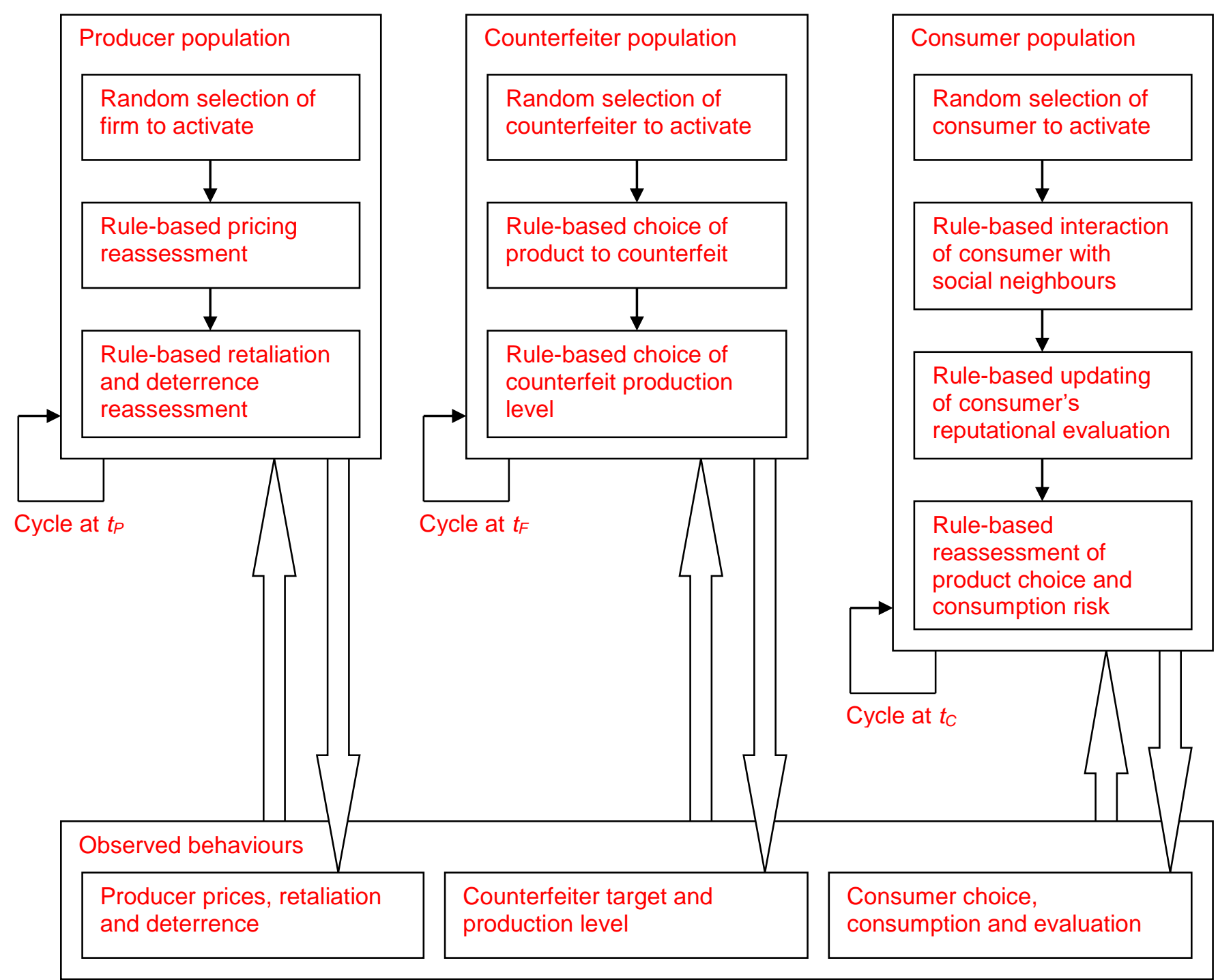

Figure 2. A schematic representation of the simulation

The primary public safety outcomes are take two forms: 1) the inadvertent consumption of counterfeit products, and 2) the consumption foregone by consumers as a result of counterfeit consumption risk. In the motivating example of counterfeit pharmaceuticals, the first is probably the most significant, leading to an exposure - for example - to counterfeit drugs that are contaminated or lack the active ingredient. The second has direct consequences for the producer, representing lost revenue, but in particular cases (most obviously those of medications) also creates a public safety risk from underconsumption of protective or therapeutic products. In principle, the two outcomes, consumed counterfeits and foregone consumption, can be measured more directly as risks if it is possible to estimate the probability of a consumed counterfeit producing a fatality and, if the product is in some way protective, the probability of a fatality arising from consumption foregone. Such probabilities are entirely context-specific so there is little point in specifying them here, and the outcomes are therefore left as units of counterfeit product consumed or units of genuine product foregone. 
Figure 3 shows traces of dynamic model behavior over time in a single run for the baseline group sizes (three producers, two counterfeiters and 1000 consumers). These indicate for the two kinds of harm both the cumulative level of harm and a short-term probability over the previous period of 100 model ticks. The two kinds of risk both fluctuate, but it is clear that the foregone consumption risk follows a rising trend, whereas the counterfeit consumption risk (the darker line of the two) does not but cycles more strongly. The model ignores all pipeline effects within whatever distribution systems exist in the system, but it indicates how unstable we can expect the risks to be.

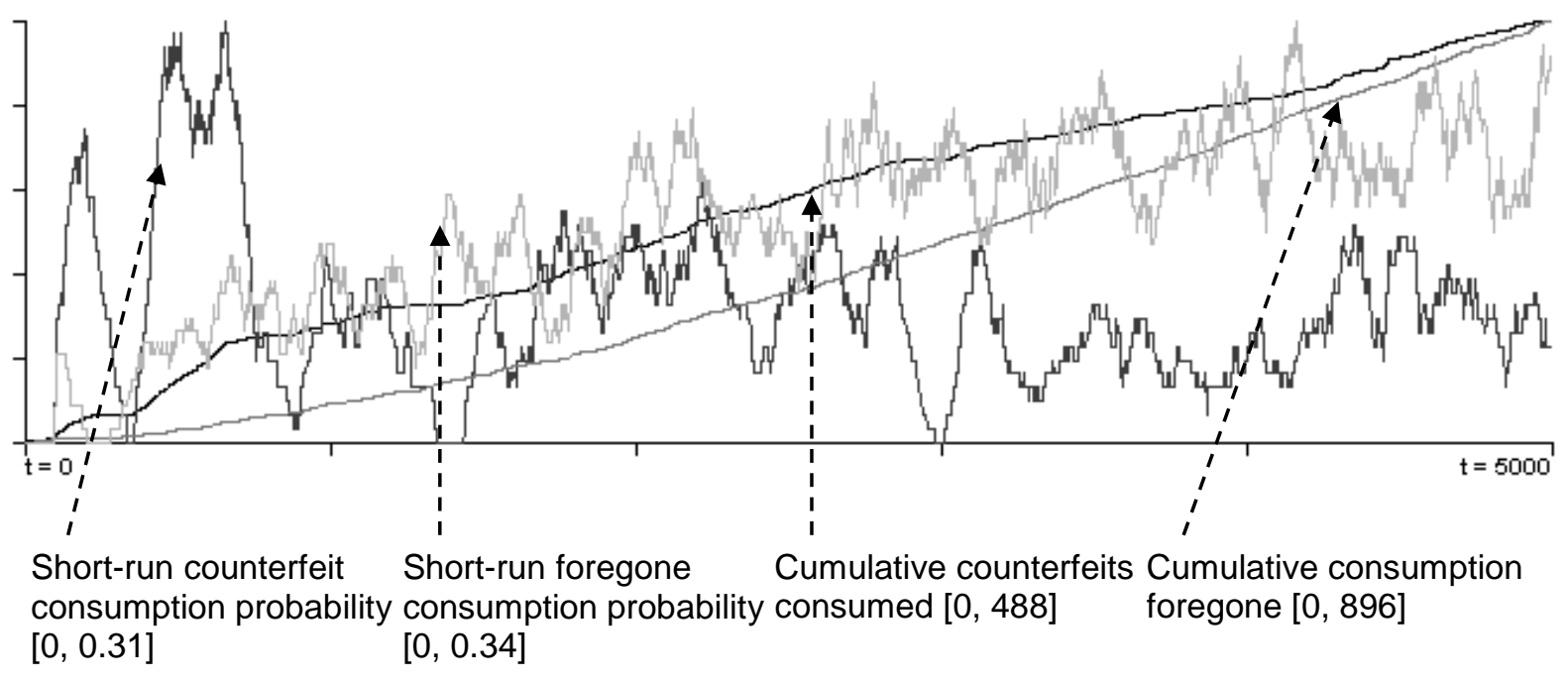

Figure 3. Traces from a single simulation run of short-term risk and accumulated harm

Figure 4 shows the trajectories of the three producers' reputations and demand levels, drawn in light grey to black as they develop over time. All producers start with similar, high levels of reputation but this declines steadily over time. They start with different levels of demand, but these converge markedly. Two producers experience rapid falls in demand, but one experiences increasing demand even as its reputation declines in the early part of the simulation period. On face value parasitism is self-limiting, in the sense that the parasite undermines the resource it exploits - its host's reputation. But in a competitive market, when a counterfeiter has undermined a producer's reputation to the point where it is a less attractive target than the original target's competitors, the counterfeiter can switch to a competitor as target. No attempt has been made to model this switching cost to counterfeiters, but such costs are likely to be low. It is the switching possibility that sustains the reputational decline. 


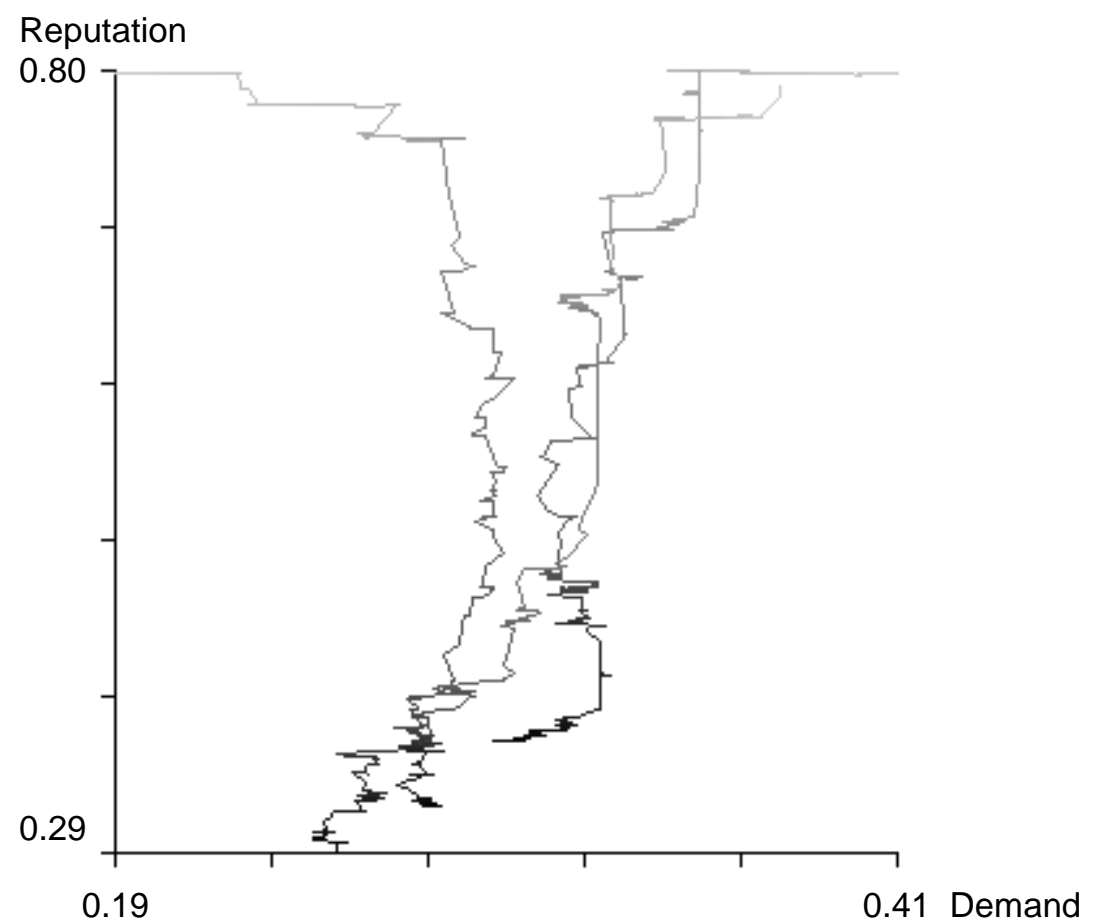

Figure 4. Trajectories of individual producer reputation and demand

\subsection{Risk and sensitivity}

In a risk model, unlike most simulations of the RBV such as Bendoly's (2007), the aim is not to discover general patterns across multiple parameterisations but to discover the behaviours of the significant outcomes - notably the ones that create harm - in a given context. The context is defined by a particular parameterisation, as in Stummer et al's (2015) agent-based model of product diffusion, subject to uncertainty in parameter values. Ford and Flynn's (2005) suggestion for assessing sensitivity to this parameterisation is to use the Pearson correlation coefficient between outcome variables and model parameters. There is a range of alternative methods for this kind of sensitivity analysis, from partial correlation coefficients (Helton and Davis, 2000), through variance-based approaches (Saltelli, 2002) to more active search-based processes (Miller, 1998). But scatter plots look straightforwardly linear, so Table 1 presents the correlation coefficients between the two riskrelevant outcomes and the parameters of the model, based on a series of 1000 runs of the simulation specified earlier, for the baseline population and two larger populations $(5,2$ and 1000 , then 10, 3 and 2000 producers, counterfeiters and consumers), labelled PS1, PS2 and PS3. 
Table 1. Product moment correlations between outcomes and parameters

\begin{tabular}{|c|c|c|c|c|c|c|c|c|}
\hline \multicolumn{2}{|c|}{ Parameter } & \multirow[t]{2}{*}{$\begin{array}{l}\text { Minima, modes } \\
\& \text { maxima }\end{array}$} & \multicolumn{3}{|c|}{$\begin{array}{l}r(\text { Counterfeits } \\
\text { consumed, Parameter) }\end{array}$} & \multicolumn{2}{|c|}{$\begin{array}{l}r \text { (Foregone } \\
\text { consumption, } \\
\text { Parameter) }\end{array}$} & \multirow[b]{2}{*}{ PS3 } \\
\hline & & & PS1 & PS2 & PS3 & PS1 & PS2 & \\
\hline$L$ & Network link mean degree & $5,10,15$ & -0.07 & -0.09 & 0.04 & 0.33 & 0.41 & 0.38 \\
\hline$M_{c f t}$ & Counterfeit reputational loss & $0.7,0.9,0.99$ & -0.03 & -0.01 & -0.05 & 0.16 & 0.16 & 0.06 \\
\hline$Y$ & Disclosure ameliorator & $0.05,0.1,0.2$ & -0.05 & -0.07 & -0.04 & -0.04 & -0.07 & -0.04 \\
\hline$M_{g e n}$ & Genuine reputational gain & $0.005,0.01,0.02$ & 0.00 & 0.00 & 0.00 & 0.00 & 0.00 & 0.00 \\
\hline$U$ & Retaliation period & $50,100,200$ & -0.39 & -0.31 & -0.26 & -0.32 & -0.25 & -0.17 \\
\hline$V$ & Retaliation trigger multiplier & $0.1,0.5,1.0$ & -0.81 & -0.85 & -0.88 & -0.73 & -0.74 & -0.68 \\
\hline$Q$ & Deterrence price multiplier & $1.0,1.5,2.0$ & -0.02 & 0.01 & -0.02 & 0.00 & 0.01 & -0.02 \\
\hline$D$ & Deterrence increment multiplier & $0.2,0.5,0.9$ & 0.02 & 0.03 & 0.04 & -0.01 & 0.03 & 0.03 \\
\hline$w$ & Deterrence trigger multiplier & $0.05,0.1,0.2$ & 0.00 & 0.00 & -0.04 & 0.01 & -0.02 & -0.03 \\
\hline
\end{tabular}

The most striking point is the general insensitivity of both outcomes to most of the model parameters - indicating that stochastic decision rules, random endowments of belief and attitude, and randomness in activation of consumers, all combine to make outcomes highly uncertain. The density of the consumer social network has no appreciable influence on consumed counterfeits, although some influence on foregone consumption. Insensitivity to network structure has been observed in other studies (Lee et al, 2013; Smith and Rand, 2018). The parameters determining reputational losses and gains from experiencing (or not) the consumption of counterfeits have surprisingly little influence, and again the influence is more on foregone consumption than on counterfeits consumed, although this is only significant for the loss and not the gain. It might be expected that the greater the reputational decrement to the experience of counterfeiting, the more consumers would be dissuaded from consumption and so the lower the overall number of counterfeits consumed. But this ignores the possibility of switching, both by consumers over short timescales and by counterfeiters over somewhat longer timescales. In terms of parameters expressing the effectiveness of producer responses to counterfeiting, there is a reasonably strong influence of a high probability of retaliation and a short retaliation period. But deterrence parameters have little influence on both outcomes. As suggested earlier, the problem for the producer is that deterrence reduces the attraction of that producer as a target for counterfeiters, but if it also increases the price of the protected product there is a countervailing increase in the attractiveness of that product for counterfeiting. And there is the switching issue: counterfeiters may switch to other producers if the deterrent works, but as they eventually undermine the reputation of those other producers it becomes increasingly attractive to switch back.

To assess risk more globally it is convenient to use a quantile-based measure resembling Value at Risk as a simple index of the risk implied in frequency distributions over total counterfeit 
consumption and foregone consumption. Both outcomes in this case are harms rather than wealth, so it makes sense to deal with the upper not lower tails of the outcome distributions, for example the 95\% quantile. The corresponding Conditional Value at Risk, which 'better captures the extreme tails' (MacKenzie, 2014), is the expected value of outcomes in the tail beyond the value at risk. Because we are dealing with harms this index would be better termed 'conditional loss potential', CLP ${ }_{0.95}$. A simulation of 1000 runs, with model parameters sampled as indicated in the previous paragraph,

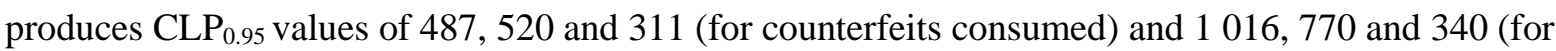
consumption foregone) for the three population sizes conditioned on the parameters taking their modal values. This says something like an expected outcome given a near worst-case scenario is that 487 counterfeits will be consumed and 1016 normal cases of consumption will be foregone, in the smaller population (PS1) model. To indicate the effect of parameter uncertainties on this, Figure 5 shows the fractional uplift in $\mathrm{CLP}_{0.95}$ from these values, first for all parameters being allowed to vary over their ranges as indicated in Table 1, and then for each parameter individually allowed to vary with all others fixed at their modal values. Parameter uncertainty increases CLP 0.95 by between 11 and $30 \%$ beyond the randomness inherent in the decision rules. As with the correlation-based sensitivity of the two types of harm, it is the retaliation trigger that dominates the effects - although for the foregone consumption risk the network density is again relevant. 


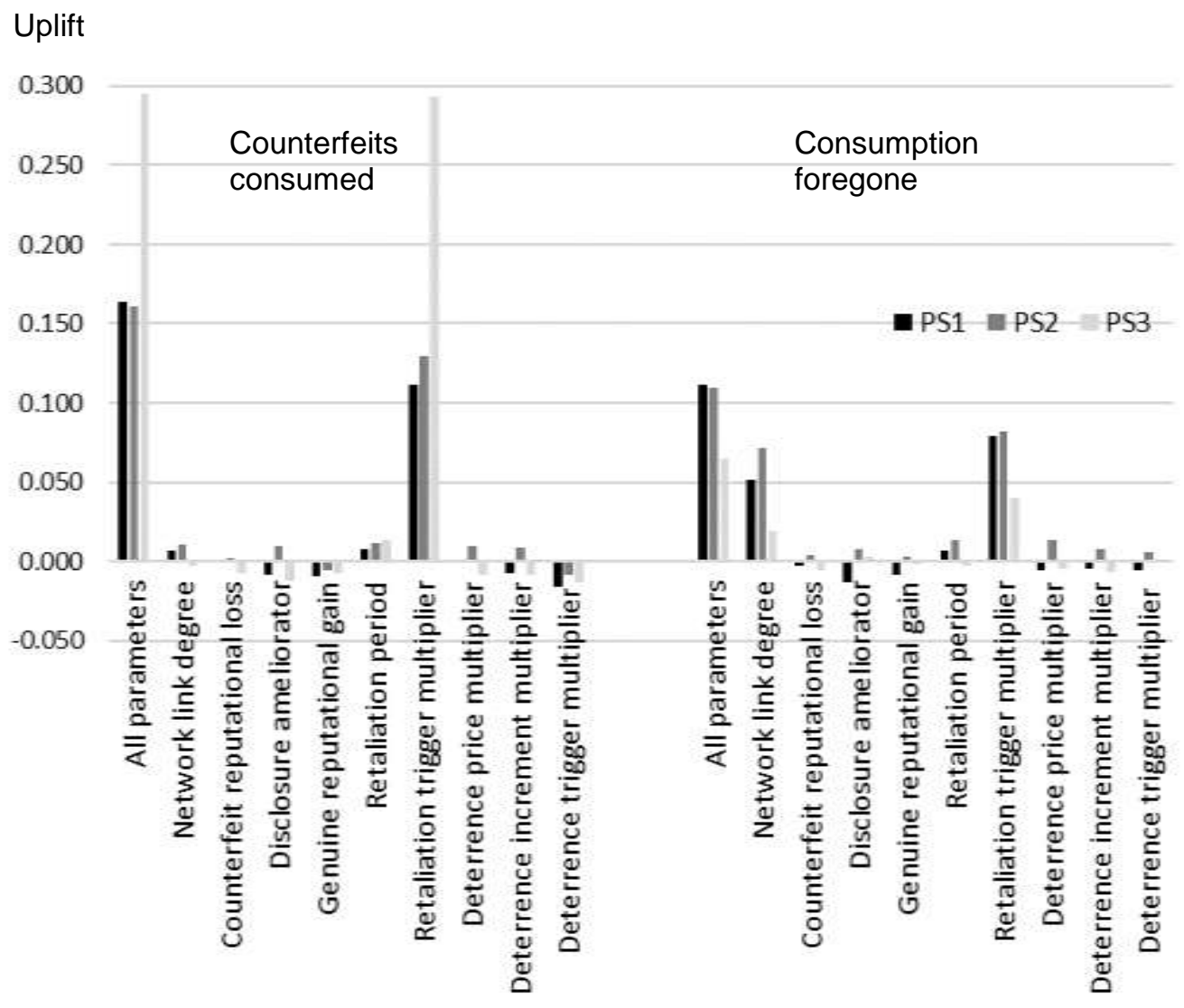

Figure 5. Fractional uplift given parameter uncertainty in $\mathrm{CLP}_{0.95}$ over counterfeits consumed (left hand panel) and consumption foregone (right hand panel)

As pointed out by one of the reviewers of this article, there are other important risks arising from counterfeiting. The reviewer mentions in particular the way in which counterfeits can overwhelm any attempt by low-cost but legitimate producers to enter a market. To deal with this, the model would need to be developed in such a way as to endogenise the firms' cost structures, especially the counterfeiters'. In markets such as pharmaceuticals, counterfeiters and generics manufacturers are likely to have vastly lower costs than legitimate producers, given product development and trialling costs. This has not been modelled here, in order to maintain a focus on the basic parasitic process. But it is a promising line of development. It is connected to the observation that impoverished consumers may consume counterfeit medicines knowingly, when it is only counterfeits that are affordable to them. If counterfeits drive out legitimate low-cost producers the reputational mechanism becomes much weaker: consumers who consume knowing that a product carrying a reputable trademark might be a counterfeit are obviously relying much less on that trademark to manage their consumption risk. There is also some suspicion (Stevenson and Busby, 2015) that generics manufacturers are engaged in 
counterfeiting, indicating that some of the resource they could be devoting to legitimate low cost manufacture is instead being used to produce counterfeits.

\section{Discussion and conclusion}

\subsection{Insights provided by the model}

The main reason for modelling in this case is to make an extension of the RBV coherent by developing what Bunge (1997) calls a 'mechanismic' model. The resource-based theory of counterfeiting is not a static correlation between the value of the reputational resource and the degree of counterfeit penetration but a co-evolution over time of counterfeit penetration and the competitive fortunes of the targeted producers. This approach is consistent with a shift of social theorizing from 'nomothetic to generative explanations' and 'variable-based to configurative ontologies' (Cederman, 2005). And it enables an analysis that neither has to assume consumers share no information with each other, nor has to assume they fully pool their experience (Liebeskind and Rumelt, 1989). This contrasts with models of the resource-based view such as Makadok's (2001) - which treats all actors other than two competing firms as exogenous influences, modelling the value of a resource as a single, aggregate variable not as the operation of a complex process. And it contrasts with Adner and Zemsky's (2006) approach, which represents resource value as some functional expression of what consumers get from some product improvement - instead of depicting how this value is realised in the mechanisms through which the consumer's reputational evaluation affects their choice to consume.

The model also helps to explore the consequences of making the necessary assumptions. In this case, the two primary, direct measures of harm due to parasitism are the cumulative numbers of counterfeits consumed and the cumulative consumption foregone. These measures are correlated but not deterministically related so it is possible, if unusual, to experience high levels of foregone consumption when counterfeit penetration has been low. And the two kinds of harm have different dynamics - one cycling strongly, one cycling less strongly with a pronounced growth over time. Moreover, although parasitism is self-limiting, counterfeiters can switch between producers as hosts, probably at low cost, so perpetuating a general reputational decline in a market in the absence of other actions. Similarly, the possibility that consumers switch, as producer reputations change due to parasitism, means that the consumption of counterfeits is insensitive to how much a consumer's experience of counterfeiting damages the targeted producer's reputation. It is similarly insensitive to processes of deterrence undertaken by producers individually. These are potentially important limits to how far consumers and producers can control the associated risk.

A third, collateral benefit to modelling is being able to identify connections and parallels with other lines of work. Credit is due to one of the anonymous reviewers for the insight that there is a close connection between parasitism and free-riding, both inter- and intra-organizational, as found in 
attempts at group collaboration - and characteristically modelled with game theory (Al-Dhanhani et al, 2014). This shows how collaboration is impeded in various ways by behaviour that appears to be parasitic - in the sense that one entity (individual or organizational) exploits a resource properly belonging to another, or fails to share collaboratively useful informational resources (Bendoly, 2014). It is a reminder that various resources - reputational, informational and other - are not just exploited by impersonation, as in counterfeiting, but also, more weakly but still successfully, by association. An example in supply chain operations is provided by Rokkan and Buvik's (2003) study.

\subsection{The relationship with the prior resource-based view}

One of the main issues in the RBV literature is that of resource erosion (Dierickx and Cool, 1989). Bendoly (2007) refers simply to a 'natural depreciation' of resources and, in Rahmandad's (2012) model of capability development, erosion is represented by a basic mathematical function. Adner and Zemsky (2006) suggested that how resource value evolves over time generally is 'largely unexplored'. But in this study the erosive process is central to the model and the theory it illustrates. Erosion is not the operation of an analytical function: it is the product of a complex interaction among producers, consumers and counterfeiting. It is endogenous to a system of interacting actors, and this helps show how erosion arises from the joint operation of all these actors' decision rules.

Another connection with prior work is that this study reiterates Ahuja and Katila's (2004) observation on the evolutionary emergence of resources in a process of adapting to idiosyncratic circumstances. The context is very different from Ahuja and Katila's (2004). But it similarly makes the point that resource heterogeneity - in this case variation in reputational resource - is a product of a firm co-evolving with an ecology, and at any given time the ecology is itself a product of the prior coevolution. This ecology is highly idiosyncratic, being strongly shaped by a sequence of random conditions. Yet, at the same time, and as Eisenhardt and Martin (2000) emphasize, there is commonality as well as idiosyncrasy in the conditions experienced by different firms. The parasitism experienced by one firm is readily transferred to its conspecifics as the model develops over time. And the reputational resource, although instantaneously heterogeneous and following unique trajectories across the producers, is shaped by a common generative process.

It is worth observing that parasitism does not change the way the classical resource-based view of legitimate competition works: it co-exists with it and changes its outcomes, but the instrumental properties of a resource - its inimitability, rarity, non-substitutability and value - remain:

1. The inimitability of a producer's quality reputation is inherent in the model in the sense that a competitor cannot copy or acquire it as though it were available for sale in some factor market. Reputation is directed to a firm uniquely, and rises or falls according to consumer beliefs and experience. Counterfeiters do not try to imitate this reputational resource: they exploit it by impersonating the host, imitating the host's products (not its resources) and using its trademark. Heterogeneity of reputation thus remains a basis of competition among legitimate producers. 
2. As far as rarity is concerned, a firm's reputation is unique. It may happen to have the same level of reputation as a competitor as a result of its historical development, but its reputation is its reputation alone. In the real world there is more complexity, and it may be that a firm's reputation is really a whole industry's reputation that is attributed to a specific firm. In some sense this is an internalization of resources that belong outside the firm (Bendoly, 2007; Dyer and Singh, 1998). It may also be that a competitor receives some reflected benefit from a firm's reputation if consumers assume a competitor is likely to achieve the same kind of quality level. But this does not alter the competitive benefit of whatever rarity is achieved in practice .

3. The property of non-substitutability arises in the model because consumers always choose by reputation, given its summarising value (Teece et al, 1997). There is no possible substitute for reputation: when it is diminished producers cannot produce the same kind of value in some other way. Again in reality there are some complexities that do not figure in the model. In industries such as pharmaceuticals, firms that lack a specific quality reputation can partly substitute for this with the reputation of regulatory authorities, giving consumers the confidence to consume the products of unknown firms if they trade through reasonably transparent channels. But this effect applies to all members of the same industry so is not heterogeneously distributed.

4. Reputational resources are innately valuable in the model because of the obvious point that reputation occurs in the consumer's decision rule. This value does not lose its relevance to the firm's competitive advantage when parasitism occurs. A unit of reputation is as valuable in securing revenue as it would be without parasitism. Parasitism does diminish the number of units of reputation each producer enjoys and therefore the net value they capture. So it does reduce the returns from this competition, and the simulation suggested it can reduce the heterogeneity of the resource distribution over the competing firms. But whatever resource heterogeneity remains plays the same role as before in strategic competition and acquires the same value.

What does not remain the same, of course, is risk. A producer's quality reputation is an important, perhaps the most important, way in which consumers manage the risk of information asymmetry and of defective or contaminated products. The erosion of its value as a resource to the producer, through the parasitic process, is accompanied by the erosion of its usefulness as a risk control - and by the increase in risks such as those arising from defective or contaminated products. Traditionally, resource-based value theory attempts to describe and explain firms' competitive success in terms of the heterogeneous distribution of resources like quality reputation. But we need to look more widely at what happens to these resources in a firm's ecology - at parasitism in particular - and we need to look more widely at the consequences of such processes, especially erosive processes that accompany parasitism, including consequences such as risk to public safety. 


\subsection{Intended contributions}

The intended contributions of this study are as follows:

1) To make a case for extending the resource-based view to deal with parasitic activity, particularly counterfeiting, as well as competition. Counterfeiting is focussed on a producer's reputational resource, so it seems natural to draw on the resource-based view to deal with counterfeiting, and this enables us to theorize about competition and parasitism as co-evolving phenomena.

2) To substantiate an extended resource-based theory with a model of the mechanisms underlying this co-evolution. This provides a generative theory, emphasizing the interaction of producers, their competitors, consumers and counterfeiters, and how this interaction constitutes competition and parasitism as processes over time. The results are outcomes such as counterfeit penetration and market breakdown. Taking a computational, agent-based approach produces an essentially algorithmic rather than analytical model (Grimm et al, 2015), in which actors can be given naturalistic, heuristic decision rules rather than being attributed with formal economic rationality.

3) To suggest a way of using the model in a straightforward probabilistic risk assessment. Risk is central to the model - risk to consumers from information asymmetry, risk of reputation as a risk control becoming undermined as a result of parasitism, risk of market penetration by counterfeits and risk of exposure to contaminated or defective products. The model produces frequency distributions over model outcomes that can be directly related to the effects on public safety.

\subsection{Limitations of the work}

Various points were made in the course of the model development on how the model might be made more complex and more veridical. Complexities and variations in counterfeiters' cost structures, for instance, were ignored. The issues involved in balancing parsimony and veridicality are dealt with in detail by Carley (2009), and more recently by Miller (2015). The essential point for this study has been to show how theory can be extended to deal with an important phenomenon that it had not formerly incorporated, and to show how models can be set up to apply it to specific cases. The emphasis has been on relative simplicity (Burton and Obel, 2011) in the interests of reducing epistemic opacity (Miller, 2015). As with other work on the resource-based view, the model is stylized and incorporates many simplifications, but the aim is tractability and a concentration on the core issues that need exploring. There is nothing stopping further work dealing with the simplifications, for example incorporating other actors such as product distributors and state authorities. Law making (for example EU, 2011) can obviously have an important direct effect on reputational evaluations, for example, as well as indirect effects via deterrents to parasites. The model could also incorporate more complex behaviours available to producers, particularly collective deterrent action.

The study ignores various additional processes that shape resources over time. The lifecycle that characterizes resources and capabilities (Helfat and Peteraf, 2003), incorporating pivotal events 
like renewal and retrenchment, are absent from the model. In reality, the influence of parasitism on the reputational resource is superimposed on such a lifecycle, and may well interact with it. A related omission is a proper treatment of endowment. Coen and Maritan's (2011) model, although it represents a very different context, shows that the endowment of an operational capability matters, sometimes more than the dynamic capability that updates it. In the counterfeiting model, the reputational resource is operational in the sense that it contributes directly to competitive advantage. This ignores reputation as a dynamic capability or resource. Having a reputation for producing with high quality makes a firm a more attractive technology development partner for other firms, a more attractive employer for capable individuals, and a more attractive investment for funders. A promising line of future work would be to explore the combined operational and dynamic nature of the reputational resource, and to assess the relative importance of endowment.

Although it has been suggested that the model naturally supports probabilistic risk assessment, there are some important caveats here as well. Most obviously, a risk assessment is carried out to reflect the specific circumstances of the system under analysis as much as general theories of processes like parasitism. As the EU falsified medicines directive (EU, 2011) indicates, 'risk assessments should consider aspects such as the price of the medicinal product; previous cases of falsified medicinal products being reported in the Union and in third countries; the implications of a falsification for public health, taking into account the specific characteristics of the products concerned; and the severity of the conditions intended to be treated'. This could be further extended to consider aspects such as the specific nature of the supply chains into which counterfeits are infiltrated, and how the regions in which they operate are likely to influence the penalties counterfeiters face.

Nonetheless, although there are clear limitations, the study makes a start on recognizing that the resources that are central to competition between firms are equally central to illicit, parasitic attacks on those firms, and also central to how consumers protect themselves against the risks of consuming poor or even dangerous products. It indicates how we might develop and extend a resource-based view that has hitherto been focussed strongly on resources underpinning competition, not on how those same resources - reputational resources in particular - matter to a wider ecology.

\section{References}

Abdelghany, A., Abdelghany, K., Mahmassani, H., Alhalabi, W. (2014). Modeling framework for optimal evacuation of large-scale crowded pedestrian facilities. European Journal of Operational Research, 237: 1105-1118.

Adner, R. and Zemsky, P. (2006). A demand-based perspective on sustainable competitive advantage. Strategic Management Journal, 27: 215-239. 
Ahuja, G. and Katila, R. (2004). Where do resources come from? The role of idiosyncratic situations. Strategic Management Journal, 25: 887-907.

Akerlof, G. A. (1970). The market for 'lemons': Quality uncertainty and the market mechanism. Quarterly Journal of Economics, LXXXIV: 488-500.

Al-Dhanhani, A., Mizouni, R., Otrok, H. and Al-Rubaie, A. (2014). A game theoretical model for collaborative groups in social applications. Expert Systems with Applications, 41: 5056-5065.

Alexy, O., West, J., Klapper, H. and Reitzig, M. (2018). Surrendering control to gain advantage: reconciling openness and the resource-based view of the firm. Strategic Management Journal, 39: 1704-1727.

Amini, M., Wakolbinger, T., Racer, M. and Nejad, M.G. (2012). Alternative supply chain productionsales policies for new product diffusion: an agent-based modeling and simulation approach. European Journal of Operational Research, 216: 301-311.

Arend, R.J. (2015). Mobius' edge: infinite regress in resource-based and dynamic capabilities views. Strategic Organization, 13, 75-85.

Arend, R.J. and Lévesque, M. (2010). Is the resource-based view a practical organizational theory? Organization Science, 21: 913-930.

Axelrod, R. (1997). The Complexity of Cooperation: Agent-Based Models of Competition and Collaboration. Princeton University Press (Princeton NJ).

Barabasi, A. and Albert, R. (1999). Emergence of scaling in random networks. Science, 286: 509.

Barney, J. (1991). Firm resources and sustained competitive advantage. Journal of Management, 17: 99-120.

Barney, J. B. (1999). How a firm's capabilities affect boundary decisions. Sloan Management Review, 40: $137-145$.

Barney, J.B., Ketchen, D.J. and Wright, M. (2011). The future of resource-based theory: revitalization or decline? Journal of Management, 37: 1299-1315.

Bendoly, E. (2007). Resource enablement modeling: implications for studying the diffusion of technology. European Journal of Operational Research, 179: 537-553.

Bendoly, E. (2014). System dynamics understanding in projects: information sharing, psychological safety, and performance effects. Production and Operations Management, 23: 1352-1369.

Bowman, C. and Ambrosini, V. (2003). How the resource-based and the dynamic capability views of the firm inform corporate-level strategy. British Journal of Management, 14: 289-303.

Branco, M.C. and Rodrigues, L.L. (2006). Corporate social responsibility and resource-based perspectives. Journal of Business Ethics, 69: 111-132.

Bromiley, P. and Rau, D. (2016). Operations management and the resource based view: another view. Journal of Operations Management, 41: 95-106.

Bunge, M. (1997). Mechanism and explanation. Philosophy of the Social Sciences, 27: 410-465.

Burton, R.M. and Obel, B. (2011). Computational modeling for what-is, what-might-be, and what- 
should-be studies - and triangulation. Organization Science, 22: 1195-1202.

Busby, J.S., Onggo, B.S. and Liu, Y. (2016). Agent-based computational modelling of social risk responses. European Journal of Operational Research, 251: 1029-1042.

Cabral, L. (2016). Living up to expectations: corporate reputation and persistence of firm performance. Strategy Science, 1: 2-11.

Cannon, A.R., Reyes, P.M., Frazier, G.V., and Prater, E.L. (2008). RFID in the contemporary supply chain: Multiple perspectives on its benefits and risks. International Journal of Operations and Production Management, 28: 433-454.

Carley, K. (2009). Computational modeling for reasoning about the social behavior of humans. Computational and Mathematical Organization Theory, 15: 47-59.

Casola, L., Kemp, S. and Mackenzie, A. (2009). Consumer decisions in the black market for stolen or counterfeit goods. Journal of Economic Psychology, 30: 162-171.

Cederman, L.-E. (2005). Computational models of social forms: advancing generative process theory. American Journal of Sociology, 110: 864-893.

Chaudhry, P.E. and Stumpf, S.A. (2011). Consumer complicity with counterfeit products. Journal of Consumer Marketing, 28: 139-151.

Chauradia, A.J., Echambadi, R., Milewicz, C. and Ganesh, J. (2018). Advancing the resource-based view: human capital investments and consumer satisfaction. Academy of Management Proceedings, 2018, 1, doi: https://doi.org/10.5465/AMBPP.2018.13131abstract.

Cho, S.-H., Fang, X. and Tayur, S. (2015). Combating strategic counterfeiters in licit and ellicit supply chains. Manufacturing and Service Operations Management, 17: 273-289.

Coen, C.A. and Maritan, C.A. (2011). Investing in capabilities: the dynamics of resource allocation. Organization Science, 22: 99-117.

Cordell, V.V., Wongtada, and Kieschnick, R.L. (1996). Counterfeit purchase intentions: Role of lawfulness attitudes and product traits as determinants. Journal of Business Research, 35: 41-53. Cuomo, R.E., Mackey, T.K. (2014). An exploration of counterfeit medicine surveillance strategies guided by geospatial analysis: lessons learned from counterfeit Avastin detection in the US drug supply chain. BMJ Open, 4, e006657. Doi:10.1136/bmjopen-2014-006657.

Davis, J.P., Eisenhardt, K.M. and Bingham, C.B. (2007). Developing theory through simulation methods. Academy of Management Review, 32: 480-499.

Dierickx, I. and Cool, K. (1989). Asset stock accumulation and sustainability of competitive advantage. Management Science, 35: 1504-1511.

DiMase, D., Collier, Z.A., Carlson, J., Gray, R.B. and Linkov, I. (2016). Traceabiity and risk analysis strategies for addressing counterfeit electronics in supply chains for complex systems. Risk Analysis, 36: $1834-1843$.

Dulleck, U. and Kerschbamer, R. (2006). On doctors, mechanics and computer specialists: the economics of credence goods. Journal of Economic Literature, 44: 5-42. 
Dyer, J.H. and Singh, H. (1998). The relational view: Cooperative strategy and sources of interorganizational competitive advantage. Academy of Management Review, 23: 660-679. Eisenhardt, K.M. and Martin, J.A. (2000). Dynamic capabilities: what are they? Strategic Management Journal, 21: 1105-1121.

Epstein, J.M. (2008). Why model? Journal of Artificial Societies and Social Simulation, 11: 12. EU (2011). Directive 2011/62/EU of the European Parliament and of the Council. Official Journal of the European Union, L174/74. Last accessed on 24/9/18 at https://ec.europa.eu/health/humanuse/falsified_medicines_en.

Feinberg, R.M. and Rousslang, D.J. (1990). The economic effects of intellectual property right infringements. Journal of Business, 63: 79-90.

Fejes, Z.L. and Wilson, J.M. (2013). Cue utilization in the product authentication process: a framework and research agenda for product counterfeit prevention. International Journal of Comparative and Applied Criminal Justice, 37: 317-340.

Ford, A. and Flynn, H. (2005). Statistical screening of system dynamics models. System Dynamics Review, 21: 273-303.

Freudenberg, W. R. (1993). Risk and recreancy: Weber, the division of labour, and the rationality of risk perceptions. Social Forces, 71: 909-932.

Gigerenzer, G. and Goldstein, D.G. (1996). Reasoning the fast and frugal way: models of bounded rationality. Psychological Review, 103: 650-669.

Gigerenzer, G. and Brighton, H. (2009). Homo heuristicus: why biased minds make better inferences. Topics in Cognitive Science, 1: 107-143.

Grimm, V., Revilla, E., Berger, U., Jeltsch, F., Mooij, W.M., Railsback, S.F., Thulke, H.-H., Weiner, J., Wiegand, T. and DeAngelis, D. (2005). Pattern-oriented modelling of agent-based complex systems: lessons from ecology. Science, 310: 987-991.

Grossman, G.M. and Shapiro, C. (1988a). Counterfeit-product trade. American Economic Review, 78: 59-75.

Grossman, G.M. and Shapiro, C. (1988b). Foreign counterfeiting of status goods. Quarterly Journal of Economics, 103: 79-100.

Hardcopf, R., Gonçalves, P., Linderman, K. and Bendoly, E. (2017). Short-term bias and strategic misalignment in operational solutions: Perceptions, tendencies, and traps. European Journal of Operational Research, 258: 1004-1021.

Helfat, C.E. and Peteraf, M.A. (2003). The dynamic resource-based view: capability lifecycles. Strategic Management Journal, 24: 997-1010.

Helton, J.C. and Davis, F.J. (2000). Sample-based methods. In Saltelli, A., Chan, K. and Scott, E.M. (eds.). Sensitivity Analysis, Wiley (Chichester, UK), pp. 101-154.

Hitt, M.A., Xu, K. and Carnes, C.M. (2016). Resource based theory in operations management research. Journal of Operations Management, 41: 77-94. 
Jackson, G., Patel, S. and Khan, S. (2012). Assessing the problem of counterfeit medications in the United Kingdom. International Journal of Clinical Practice, 66: 241-250.

Juillet, Y. and Vlasto, A.-P. (2005). Counterfeiting of medicinal drugs: issues and threats.

Fundamental and Clinical Pharmacology, 19: 621-624.

Kor, Y.Y., Mahoney, J.T. and Michael, S.C. (2007). Resources, capabilities and entrepreneurial perceptions. Journal of Management Studies, 44: 1187-1212.

Kraaijenbrink, J., Spender, J.-C. and Groen, A.J. (2010). The resource-based view: a review and assessment of its critiques. Journal of Management, 36: 349-372.

Kull, A.J., Mena, J.A. and Korchun, D. (2016). A resource-based view of stakeholder marketing. Journal of Business Research, 69: 5553-5560.

Lado, A.A., Boyd, N.G., Wright, P. and Kroll, M. (2006). Paradox and theorizing within the resourcebased view. Academy of Management Review, 31: 115-131.

Lahiri, A. and Dey, D. (2013). Effects of piracy on quality of information goods. Management Science, 59: 245-264.

Lavie, D. (2006). The competitive advantage of interconnected firms: an extension of the resourcebased view. Academy of Management Review, 31: 638-658.

Lee, K., Kim, S., Kim, C. O., \& Park, T. (2013). An agent-based competitive product diffusion model for the estimation and sensitivity analysis of social network structure and purchase time distribution. Journal of Artificial Societies and Social Simulation, 16: 3.

Liang, B.A. (2006). Fade to black: importation and counterfeit drugs. American Journal of Law and Medicine. 32: 279-323.

Liebeskind, J. and Rumelt, R.P. (1989). Markets for experience goods with performance uncertainty. RAND Journal of Economics, 20: 601-621.

Loewenstein, G. and Mather, J. (1990). Dynamic processes in risk perception. Journal of Risk and Uncertainty, 3: 155-175.

Macal, C.M. and North, M.J. (2010). Tutorial on agent-based modelling and simulation. Journal of Simulation, 4: 151-162.

Mackenzie, S. (2010). Counterfeiting as corporate externality: Intellectual property crime and global insecurity. Crime, Law and Social Change, 54: 21-38.

MacKenzie, C.A. (2014). Summarizing risk using risk measures and risk indices. Risk Analysis, 34, $2143-2162$.

Mackey, T. K., Liang, B. A., York, P. and Kubic, T. (2015). Counterfeit drug penetration into global legitimate medicine supply chains: A Global Assessment. The American Journal of Tropical Medicine and Hygiene, 92 (Supplement 6): 59-67.

Mackey, T.K., Cuomo, R., Guerra, C. and Liang, B.A. (2015). After counterfeit Avastin - what have we learned and what can be done? Nature Reviews Clinical Oncology, 12: 302-308. 
Macy, M.W. and Willer, R. (2002). From factors to actors: computational sociology and agent-based modelling. Annual Review of Sociology, 28: 143-166.

Makadok, R. (2001). Toward a synthesis of the resource-based and dynamic-capability views of rent creation. Strategic Management Journal, 22: 387-401.

Mesquita, L.F., Anand, J. and Brush, T.H. (2008). Comparing the resource-based and relational views: knowledge transfer and spillover in vertical alliances. Strategic Management Journal, 29: 913941.

Miller, J.H. (1998). Active nonlinear tests (ANTs) of complex simulation models. Management Science, 44: 820-830.

Miller, K.D. (2015). Agent-based modeling and organization studies: a critical realist perspective. Organization Studies, 36: 175-196.

Moussaid, M., Brighton, H. and Gaissmaier, W. (2015). The amplification of risk in experimental diffusion chains. Proceedings of the National Academy of Sciences, 112, 5631-5636.

Muter, B.A., Gore, M.L. and Riley, S.J. (2013). Social contagion of risk perceptions in environmental management networks. Risk Analysis, 33: 1489-1499.

Nagarajan,M.,Shaw,D. and Albores,P.(2012). Disseminating a warning message to evacuate: A simulation study of the behaviour of neighbours. European Journal of Operational Research, 220: 810-819.

Nelson, P. (1970). Information and consumer behavior. Journal of Political Economy, 78: 311-329.

Newbert, S.L. (2007). Empirical research on the resource-based view of the firm: an assessment and suggestions for future research. Strategic Management Journal, 28: 121-146.

Newton, P.N., Green, M.D., Fernández, F.M., Day, N.P.J. and White, N.J. (2006). Counterfeit antiinfective drugs. Lancet Infectious Diseases, 6: 602-13.

Nuclear Safety (2013). Counterfeit, fraudulent and suspect items. Canadian Nuclear Safety Commission, $17^{\text {th }}$ March. Accessed at http://nuclearsafety.gc.ca/eng/resources/educationalresources/feature-articles/counterfeit-fraudulent-and-suspect-items.cfm on $26^{\text {th }}$ November 2015. Pacheco-de-Almeida, G. and Zemsky, P. (2007). The timing of resource development and sustainable competitive advantage. Management Science, 53: 651-666.

Pinho de Lima, F.R., Lago Da Silva, A., Filho, M.G. and Dias, E.M. (2018). Systematic review: resilience enablers to combat counterfeit medicines. Supply Chain Management: An International Journal, 12: 117-135.

Poortinga, W. and Pidgeon, N.F. (2004). Trust, the asymmetry principle, and the role of prior beliefs. Risk Analysis, 24: 1475-1486.

Priem, R.L. and Butler, J.E. (2001). Is the Resource-Based "View" a useful perspective for strategic management research? Academy of Management Review, 26: 22-40.

Qian, Y. (2008). Impacts of entry by counterfeiters. Quarterly Journal of Economics, 123: 1577-1609. 
Qian, Y., Gong, Q., \& Chen Y.X. (2015). Untangling searchable and experiential quality responses to counterfeits. Marketing Science, 34: 522-538.

Rahmandad, H. (2012). Impact of growth opportunities and competition on firm-level capability development trade-offs. Organization Science, 23: 138-154.

Rahmandad, H. and Sterman, J. (2008). Heterogeneity and network structure in the dynamics of diffusion: comparing agent-based and differential equation models. Management Science, 54: 9981014.

Ramello, G.B. (2006). What's in a sign? Trademark law and economic theory. Journal of Economic Surveys, 20: 547-565.

Roberts, P. W. and Dowling, G.R. (2002). Corporate reputation and sustained superior financial performance. Strategic Management Journal, 23: 1077-1093.

Rokkan, A.I. and Buvik, A. (2003). Inter-firm collaboration and the problem of free riding behaviour: an empirical study of voluntary retail chains. Journal of Purchasing and Supply Management, 9: 247256.

Rumelt, R.P. (1984). Towards a strategic theory of the firm. In Lamb, R.B. (ed.), Competitive Strategic Management, Prentice-Hall (Englewood Cliffs, NJ), pp. 556-570.

Saltelli, A. (2002). Sensitivity analysis for importance assessment. Risk Analysis, 22: 579-590.

Scherer, C.W and Cho, H.C. (2003). A social network contagion theory of risk perception. Risk Analysis, 23: 261-267.

Scott, S.V. and Walsham, G. (2005). Reconceptualizing and managing reputation risk in the knowledge economy: toward reputable action. Organization Science, 16: 308-322.

Senate (2012). Inquiry into counterfeit electronic parts in the Department of Defense supply chain. Report 112-167 of the Committee on Armed Services, United States Senate. US Government Printing Office, Washington.

Smith, E.B. and Rand, W. (2018). Simulating macro-level effects from micro-level observations. Management Science, Articles in Advance, https://doi.org/10.1287/mnsc.2017.2877.

Stevenson, M. and Busby, J. (2015). An exploratory analysis of counterfeiting strategies. International Journal of Operations and Production Management, 35: 110-144.

Stummer, C., Kiesling, E., Guenther, M. and Vetschera, R. (2015). Innovation diffusion of repeat purchase products in a competitive market: an agent-based simulation approach. European Journal of Operational Research, 245: 157-167.

Teece, D.J., Pisano, G. and Shuen, A. (1997). Dynamic capabilities and strategic management. Strategic Management Journal, 18:509-534.

Tonn, G.L. and Guikema, S.D. (2018). An agent-based model of evolving community flood risk. Risk Analysis, 38: 1258-1278.

Tversky, A. and Kahneman, D. (1974). Heuristics and biases. Science, 185: 1124-1131.

Veloutsou, C. and Bian, X. (2008). A cross-national examination of consumer perceived risk in the 
context of non-deceptive counterfeit brands. Journal of Consumer Behavior, 7: 3-20.

Weiss, C. (2006). Price inertia and market structure: empirical evidence from Austrian manufacturing. Applied Economics, 25, 1175-1186.

Wernerfelt, B. (1984). A resource-based view of the firm. Strategic Management Journal, 5: 171-180.

Wernerfelt, B. (2016). Adaptation, Specialization, and the Theory of the Firm: Foundations of the Resource-Based View. Cambridge University Press (Cambridge, UK).

Wilson, J.M., Sullivan, B.A. and Hollis, M.E. (2016. Measuring the "unmeasurable": approaches to assessing the nature and extent of product counterfeiting. International Criminal Justice Review, 26: 259-276.

Wood, A.D., Mason, C.F. and Finnoff, D. (2016). OPEC, the Seven Sisters, and oil market dominance: an evolutionary game theory and agent-based modeling approach. Journal of Economic Behavior and Ogranization, 132: 66-78.

WTO. (2011). Available at www.wto.org/english/thewto_e/glossary_e/glossary_e.htm, (last accessed on $15^{\text {th }}$ March, 2011).

\section{Notation}

\begin{tabular}{|l|l|l|l|}
\hline \multicolumn{2}{|l|}{ Variables } & \multicolumn{2}{l|}{} \\
\hline$P$ & Producers & $p$ & producer \\
\hline$r_{p}$ & $p^{\prime}$ 's reputation & $q_{p}$ & $q$ 's price \\
\hline$z_{p}$ & Demand for p's products & $Z(p)$ & $p^{\prime}$ 's consumer base \\
\hline$i_{p}$ & $p^{\prime}$ 's investment in deterrence & $y_{p}$ & $p^{\prime}$ 's disclosure of counterfeits \\
\hline$b_{p}$ & Proportion of $p$ 's products counterfeit & $w_{p, t}$ & $p^{\prime}$ 's prior price weight at $t$ \\
\hline & & & \\
\hline$C$ & Consumers & $c$ & consumer \\
\hline$G$ & Graph of network over $C$ & $N(c)$ & $c^{\prime}$ 's neighbourhood \\
\hline$r_{c p}$ & $c^{\prime}$ 's evaluation of $p$ & $k_{c}$ & $c^{\prime}$ 's choice of producer \\
\hline$y_{c}$ & $c$ 's credulity & $x_{c}$ & $c^{\prime}$ 's experience of consuming a counterfeit \\
\hline$l_{c}$ & $c^{\prime}$ 's consumption & & \\
\hline & & & \\
\hline$F$ & Counterfeiters & $f$ & Counterfeiter \\
\hline$u_{f}$ & $f$ 's choice of target & $e_{f}$ & $f$ 's choice of production level \\
\hline$v_{f}$ & $f^{\prime}$ 's probability of receiving retaliation & & \\
\hline$O$ & Consumption opportunities foregone & $X$ & Accumulated consumption of counterfeits \\
\hline & & & \\
\hline Parameters & & \\
\hline
\end{tabular}




\begin{tabular}{|l|l|l|l|}
\hline$L$ & Network link mean degree & & \\
\hline$M_{\text {counterfeit }}$ & $\begin{array}{l}\text { Reputational loss from counterfeit } \\
\text { experience }\end{array}$ & $M_{\text {genuine }}$ & Reputational gain from genuine experience \\
\hline$V$ & Retaliation trigger multiplier & $U$ & Retaliation period \\
\hline$W$ & Deterrence trigger multiplier & $D$ & Deterrence increment multiplier \\
\hline$Q$ & Deterrence price multiplier & $Y$ & Recreancy ameliorator \\
\hline
\end{tabular}

